\title{
O debate sobre a democratização da educação pública e a tese da gestão democrática radical da escola
}

Carlos Felipe Nunes Moreira ${ }^{1}$ ORCID: 0000-0001-7294-149X

\section{Resumo}

Ante o extenso acúmulo de interpretações sobre gestão democrática da educação no Brasil, objetiva-se aqui apresentar uma proposta teórico-metodológica de gestão que garanta a indissociabilidade analítica entre política e economia, na qual a socialização do poder constitui mediação nuclear. Tomando por base a produção intelectual de onze principais autores de referência sobre gestão democrática no país - mais utilizados por pesquisadores que se debruçaram na temática nos últimos anos - identificaram-se tendências teórico-políticas que, do período de transição da Constituinte na década de 1980 aos dias atuais, vêm norteando as reflexões a respeito do objeto. Os resultados do estudo revelam na bibliografia pesquisada a necessidade de maior aprofundamento no que tange ao processo de solidificação de um projeto educacional antagônico, articulado com o movimento de superação da ordem capitalista. A emersão de um novo modo de produção e reprodução social que possibilite a formação intelecto-cultural integral do ser humano exige, imediatamente, o acirramento da luta pela socialização do poder políticoeconômico. Nesse sentido, ao tomar como partida o ponto máximo alcançado nas sínteses e antíteses anteriores e por meio da exploração de suas contradições, a tese da gestão democrática radial busca fornecer mediações indispensáveis aos processos que apontem para um projeto educacional alternativo de ruptura com o capitalismo e não limitado às ideias hegemônicas de democracia burguesa. Trata-se de uma gestão que se oriente por uma dimensão política inalcançável nesta sociedade, mas que valha de referência teleológica aos processos coletivos de crítica, dilatação e superação da gestão democrática atualmente possivel na ordem do capital.

\section{Palavras-chave}

Trabalho - Educação - Democracia - Democratização da política educacional - Gestão democrática da educação pública.

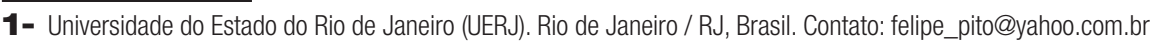




\section{The debate about democratization of public education and the thesis of radical democratic management of the school}

\section{Abstract}

In view of the extensive accumulation of interpretations on the democratic management of education in Brazil, the objective of this article is to present a theoretical-methodological management proposal that guarantees the analytical inseparability between politics and economics, in which the socialization of power constitutes nuclear mediation. Based on the intellectual production of 11 leading reference authors on democratic management in the country - widely used by researchers who have worked on the theme in recent years - theoretical and political trends have been identified which, from the transition period towards a new Constitution in the 1980s to the present day, they have been guiding the reflections about the object. The results of the study show in the bibliography reviewed the need for further development with regard to the solidification process of an antagonistic educational project, articulated with the movement to overcome the capitalist order. The emergence of a new mode of production and social reproduction in which the integral intellectual-cultural formation of the human being is possible demands, immediately, to intensify the struggle for the socialization of the political-economic power. In this regard, taking as a starting point the maximum reached in the previous syntheses and antitheses and through the exploration of its contradictions, the thesis of radial democratic management seeks to provide indispensable mediations to the processes that point to an alternative educational project that breaks with capitalism which is not limited to hegemonic ideas of bourgeois democracy. It is a management that is guided by an unattainable political dimension in this society, but that is worth of teleological reference to the collective processes of criticism, expansion and overcoming of the democratic management currently possible in the capitalist order.

\section{Keywords}

Work - Education - Democracy - Democratization of educational policy - Democratic management of public education.

\section{Introdução}

Quanto mais crítico um grupo humano, tanto mais democrático e permeável, em regra.

Paulo Freire

Este artigo é resultado de um processo de doutoramento, findado em 2018, norteado pela seguinte hipótese: tendo em vista as características da formação social brasileira, 
as particularidades da democracia no país, o projeto burguês de educação nacional determinado pelo modo de inserção do Brasil na dinâmica econômica mundial - e o viés reformista impresso em significativa parcela das lutas educacionais ao longo da história brasileira; o debate contemporâneo sobre gestão democrática da educação carece de mediação com processos que apontem para um projeto educacional antagônico de ruptura com o capitalismo e encontra-se imbricado aos limites das ideias hegemônicas de democracia liberal-burguesa.

Em contraponto, a tese defendida referencia-se pela necessidade incontornável, diante da atual fase do capitalismo monopolista, de articulação orgânica entre democratização da política educacional e superação da ordem vigente. Uma gestão democrática radical da educação que eleve a outro patamar as conquistas já objetivadas, por meio de um processo dialético de conservação-superação dessas conquistas e orientado por um tipo de democracia e de educação inconciliáveis com a ordem do capital, mas que se fortifiquem por dentro dela.

A premissa teórica deste estudo reside no entendimento de que o fundamento ontológico do debate acerca da democratização da política de educação se localiza na relação orgânica entre política e economia, na qual a socialização do poder político constitui mediação central. Sendo a educação uma dimensão ontológica do ser social, a educação formal constitui historicamente um determinado modo de conformação das relações entre as classes sociais. Analisar a educação escolarizada a partir da tradição marxista exige considerar seus determinantes sócio-históricos e, nesse sentido, possibilita identificar o seu significado social nas sociedades capitalistas. Assim como, pela mesma perspectiva teórica e resguardando a unicidade dialética entre poder político e poder econômico, a interpretação da categoria democracia permite alcançar igual finalidade.

Sustenta-se aqui que o debate sobre a democratização da educação ganha hoje novo relevo quando mediado por processos que apontem para um projeto educacional alternativo, de ruptura com o capitalismo e contraposto aos limites das ideias hegemônicas de democracia liberal-burguesa.

0 objetivo geral da investigação em tela foi realizar um balanço crítico da literatura acerca do debate referente à democratização da política de educação brasileira, do período de transição da Constituinte na década de 1980 aos dias atuais e, especificamente, identificar as tendências teórico-políticas que vêm orientando as reflexões sobre a gestão educacional democrática. A análise tomou como matéria-prima produções de autores referência no trato desse tema no país, datadas do mencionado período.

Ao considerar que o objeto desta pesquisa constitui a dimensão particular de uma totalidade complexa, o esforço metodológico empenhado apresentou como preocupação a seleção de uma amostra capaz de representar satisfatoriamente a representatividade do seu universo. 0 balanço teórico-crítico da literatura acerca do tema tomou como base as principais referências bibliográficas presentes em teses e dissertações, de todo o país, nas quais a gestão democrática compõe conceito dotado de centralidade. ${ }^{2}$

0 movimento de investigação teve como fonte o Catálogo de Teses e Dissertações da Capes, disponível para consulta no portal eletrônico da Coordenação de Aperfeiçoamento

2- A seleção considerou a análise dos títulos dos trabalhos, suas palavras-chave e resumos. 
de Pessoal de Nível Superior (CAPES). ${ }^{3} 0$ primeiro recorte refere-se à seleção da educação como área de concentração dos estudos. 0 recorte subsequente diz respeito ao ano dos trabalhos. Todos os trabalhos de conclusão disponíveis em formato digital no site, de 2013 a 2017, e dentro das condições supracitadas foram consultados. Os anos anteriores (bem como o ano de conclusão do estudo) não dispunham o acesso virtual aos trabalhos à época. Foram encontradas um total de 112 teses/dissertações. ${ }^{4}$ Nessa amostra, 385 autores diferentes que abordam a democratização da política de educação foram referenciados nas bibliografias 1.143 vezes pelos pesquisadores. ${ }^{5}$

Alguns autores foram referenciados mais vezes que outros. Os 11 autores selecionados foram aqueles mais referenciados e representam juntos 30\% do montante de 1.143. A saber, em ordem decrescente: Vitor Paro (75 vezes), Carlos Cury (39 vezes), Luiz Dourado (39 vezes), Naura Ferreira (35 vezes), Dermeval Saviani (29 vezes), Heloísa Lück (24 vezes), Dinair Hora (23 vezes), Licínio Lima (21 vezes), João Barroso (20 vezes), Dalila Oliveira (20 vezes) e Ângelo Souza (20 vezes). ${ }^{6}$ As produções selecionadas desses autores - incluindo livros, artigos e documentos - foram aquelas que conformam uma síntese maior elaborada de suas análises específicas no que tange ao processo de democratização da educação formal. $^{7}$

A análise dessas produções revelou que - no entendimento desses autores - os elementos que obstaculizam a democratização são variados e apontam para questionamentos referentes não somente à lógica organizacional hegemônica das escolas (falta de autonomia, problemas referentes à participação, ausência de eleições diretas para diretor etc.), mas também para questões macroestruturais que direcionam e determinam essa lógica (neoliberalismo, organismos internacionais, razão empresarial de gestão e administração do Estado, dentre outras). ${ }^{8}$

Também variados são os elementos que, para os autores supracitados, viabilizam a democratização. Perpassando - tal qual como antes - esferas particulares (autonomia administrativa e financeira das escolas, gestão colegiada ou autogestão, maior participação da comunidade, diálogo, respeito às diferenças, empoderamento etc.) e de âmbito mais geral (democratização da sociedade, superação das desigualdades, emancipação, transformação social e outros). ${ }^{9}$

Tal movimento de categorização e - pela mesma esteira - a construção das tendências teórico-políticas que vêm orientando as reflexões sobre a gestão educacional

\footnotetext{
3- A saber: http://catalogodeteses.capes.gov.br/catalogo-teses/\#!/.

4- Para acesso à lista dos autores das teses/dissertações pesquisadas e suas vinculações acadêmicas, confira Moreira (2018), apêndice A.

5- Para acesso ao levantamento quantitativo dos autores que abordam o tema "democratização da política educacional" referenciados pelos pesquisadores de 2013-2017, confira Moreira (2018), apêndice B.

6- 0 intuito foi contabilizar quantas vezes 0 autor y foi referenciado nas bibliografias pesquisadas. Importante mencionar que para 0 autor ser contabilizado, era preciso sua produção referenciada ter como objeto de preocupação a questão da democratização educacional. Produções referenciadas com outro(s) objeto(s) não foram contabilizadas. Produções diferentes do mesmo autor, mas com o mesmo objeto (a democratização da educação), referenciadas em uma mesma bibliografia somou uma vez apenas para o total.

7- Para acesso à tabela organizativa da literatura específica pesquisada acerca da democratização da política de educação (na qual consta o título, a autoria, 0 ano da $1^{\text {a }}$ publicação e um breve resumo de cada uma das 27 produções estudadas), confira Moreira (2018), apêndice C.

8- Para acesso ao conjunto completo dos 55 elementos que obstaculizam a democratização identificados nos textos estudados e organizado por décadas, confira Moreira (2018), tabela 1.

9- Para acesso ao conjunto completo dos 57 elementos que viabilizam a democratização identificados nos textos estudados e organizado por décadas, confira Moreira (2018), tabela 2.
} 
democrática se deram, portanto, por meio do desvelamento tanto das compreensões sobre a realidade concreta do processo de democratização, bem como das proposições voltadas à democratização da política educacional. Nessa etapa da pesquisa, optou-se por utilizar tão somente os componentes da amostra, buscando com isso o maior aprofundamento da investigação sobre o objeto e a apresentação das ideias desses autores in natura. Esse procedimento metodológico buscou ainda inserir cada produção intelectual em seu respectivo momento histórico, objetivando identificar os contextos sociopolíticos, explorar as análises conjunturais realizadas por esses próprios autores e apresentar a evolução histórica do debate dessa temática no país. ${ }^{10}$

A realização da pesquisa científıca e a identificação das sínteses e antíteses elaboradas por esse conjunto de autores acerca do processo de democratização da política de educação no Brasil, nos últimos trinta anos, possibilitaram - via método dialético - a construção da proposta de gestão democrática radical. Ao tomar como partida o ponto máximo alcançado anteriormente e por meio da exploração das contradições, a tese da gestão democrática radial busca fornecer mediações indispensáveis aos processos que apontem para um projeto educacional antagônico de ruptura com o capitalismo e não limitado às concepções hegemônicas de democracia.

Antes de apresentar aqui alguns de seus fundamentos, faz-se necessário expor, mesmo que sumariamente, as quatro tendências teórico-políticas identificadas no debate a respeito da democratização da política de educação no período estudado.

\section{Tendências do debate sobre democratização da política educacional brasileira nos últimos trinta anos}

Nas últimas três décadas, os elementos que obstaculizam a democratização, identificados nos textos estudados, apontam para o questionamento de fenômenos intrínsecos à organização tradicional da escola e da educação, não distanciados do ordenamento mais geral da sociedade. As proposições que objetivam a garantia do princípio da gestão democrática orientam-se pela necessidade de alterações político-metodológicas no âmbito organizacional do trabalho escolar (em especial o administrativo) e, em volume menor, na política de educação lato sensu. Há, de uma maneira geral, consensos nessa direção, mas conformados por vieses teóricos plurais e por sentido teleológico mais amplo por vezes impreciso.

Os resultados do estudo revelam a existência de quatro tendências na discussão localizadas socio-historicamente nos últimos trinta anos e aqui sucintamente expostas - tendencialmente presentes também, de formas diversas, no conjunto mais amplo das produções atuais e estudos posteriores sobre o tema. Considerando o total dos textos analisados, a primeira tendência a ser apresentada expressa-se de maneira residual, mas que, por estar atrelada organicamente aos interesses empresariais no que tange à compreensão e à realização da política de educação - sobretudo em países de capitalismo periférico e dependente -, tem se alastrado no âmbito educacional brasileiro a partir da

10- Confira Moreira (2018, p. 160-229). 
década de 1990. Essa tendência é marcada pela razão empresarial de gestão das escolas, sustentada pelas noções de empreendedorismo, empregabilidade, produtividade, eficiência, flexibilização, responsabilidade social, dentre outras.

A razão empresarial de gestão, de forte conotação gerencialista (cf. NEWMAN; CLARKE, 2012), apresenta embasamento direto da concepção de capital humano, em alinho ideológico com os pressupostos do Consenso de Washington e, nesse sentido, com orientações de organismos internacionais que entendem a educação como uma estratégia para diminuição das desigualdades sociais, garantia de melhores trabalhos e inclusão social. 0 consenso requerido para o fortalecimento de uma ideologia administrativa, convergente com as transformações no âmbito produtivo, tem no gerencialismo seu elemento nodal. Pela via da razão empresarial de gestão das escolas, a socialização do poder político no âmbito educacional, além de não se realizar, tende a sofrer um refluxo, mistificado por uma pseudodemocratização. Significando mudanças administrativas concretas que, ao invés de avançar a questão democrática nos espaços educacionais, a regride e se encerra no reforço da hegemonia.

A segunda tendência identificada no debate dos últimos trinta anos sobre democratização da política educacional no Brasil é aquela que aponta para a ampliação da democracia, mas tem em si um arcabouço teórico-metodológico de conservação da ordem. A tendência da democratização conservadora lida com o movimento de socialização do poder afastado dos processos de disputa entre interesses essencialmente divergentes e politicamente inconciliáveis, inerentes às sociedades organizadas em classes sociais. A lógica de garantir a gestão democrática da educação conservando suas macroestruturas antidemocráticas requer uma perspectiva teórico-política que desconsidere a centralidade de tais estruturas. Nesse sentido, a democratização é vislumbrada como o alcance do interesse de todos e da vontade geral.

Para isso, o recurso das noções de bem comum, justiça e humanização, por exemplo, desempenham papel importante tendo em vista a abordagem abstrata e socialmente acrítica. Nessa esteira, pela qual a luta de classes não adquire relevo analítico, não apenas a escola é compreendida como politicamente neutra, mas o próprio Estado - responsável então por regulamentar os conflitos sociais de modo imparcial - tende à neutralidade (tal como em pensadores liberais contratualistas, como Hobbes e Locke, por exemplo), reforçando, em última instância, o status quo.

Em diversos autores pesquisados, o movimento histórico de questionamento e superação das concepções educacionais de Rousseau na pedagogia brasileira parece não ter obtido o mesmo avanço no que se refere às suas ideias sobre democracia. Por consequência, a tradição rousseauniana exerce notada influência na tendência da democratização conservadora da política educacional. A utilização dessa vertente teórica na problematização da gestão educacional democrática, além de depositar nos indivíduos a dependência de sua transformação moral para o alcance da democratização das escolas baseada no bem comum, tende a interpretar a socialização do poder enquanto um processo de partilha que atenda aos interesses de todos.

A tendência da democratização conservadora - mais presente nas produções da década de 2000, mas também identificada nos anos 1990 e 2010 - é reforçada pelas 
correntes de pensamento do pós-modernismo (cf. JAMESON, 1993). Através do amplo movimento ideológico de "desaparecimento da história" (JAMESON, 1993) é que melhor identificam-se compreensões de democratização das escolas que, apesar de expressarem a intenção de mudanças (e por vezes de emancipação e transformação social), aprisionam-se no "presente perpétuo" (JAMESON, 1993) sem apontar alternativas contra-hegemônicas e/ou anticapitalistas de futuro. Uma democratização conservadora da sociabilidade atual que, ao incorporar acriticamente temáticas como cidadania ou aquelas de caráter multiculturalista (como empoderamento), não oferece condições para que a socialização do poder na política de educação se opere a partir de uma cultura forjada nas lutas sociais de questionamento da educação formal instituída e da ordem social estabelecida.

É nesse sentido que defender - nos moldes do pós-modernismo ou na perspectiva rousseauniana - uma educação para a cidadania como condição da democratização educacional esvazia tanto o potencial político que reside na noção de cidadania, quanto o valor social transformador da própria educação. A democratização conservadora apresenta-se, em suma, mais conservadora do que democratizante.

A terceira tendência identificada tem maior ênfase nas décadas de 1990 e 2000, mas também é pontualmente observável nos anos 1980 e 2010. Ela pode ser caracterizada pelo seu viés central de reformismo democrático. A lógica reformista, detida aos limites do escolanovismo, esteve impressa em parte relevante das lutas educacionais ao longo da história brasileira. Por essência, não se pode atribuir a ela, espontânea e mecanicamente, um caráter anticapitalista. 0 que não significa desconsiderar seu compromisso por mudanças progressistas na política de educação e sua maior democratização, exigindo, de sobremaneira, interpretar tal tendência em suas contradições.

0 reformismo democrático das escolas tem, dentre suas características, o enfrentamento do fenômeno da concentração do poder político no âmbito educacional a partir da busca de consensos democráticos por meio do esforço coletivo. Apesar de aparente semelhança com a tendência anteriormente apresentada, não se objetiva nessa a vontade geral rousseauniana, e sim uma democratização na qual o poder, decorrente da capacidade humana de agir em conjunto, torna-se elemento indispensável para a construção de uma vontade em comum. 0 pensamento de Bobbio (2000), principalmente, é basilar nesta tendência que reconhece o poder na escola como resultado de acordos firmados entre pessoas, no qual o diálogo entre os sujeitos envolvidos é condição para a realização da democracia.

A referência teórica explicitada justifica, em boa medida, a ênfase dada por essa tendência à importância da participação na gestão democrática da educação. Ainda que, por vezes, o objetivo dessa participação pareça se encerrar nela mesma, sem articulação com uma dimensão social geral ou quando tende a compreender enviesadamente democracia e/ ou democratização como mera participação. De todo modo, a defesa de maior participação nas escolas, quando não comprometida com a construção de uma cultura política contrahegemônica, além de não revelar intenção anticapitalista pode ainda servir ao reforço das orientações liberais de organismos internacionais para a educação nacional.

Por mais que os sentidos políticos de se promover uma crescente participação nas escolas possam ser variados e mesmo divergentes, a participação em si não representa 
uma ação educacional contra-hegemônica. Para o fim democrático de viés reformista, é imprescindível o incentivo à participação do maior quantitativo de sujeitos na gestão escolar, em especial por meio dos seus canais de representação coletiva de caráter consultivo e deliberativo (como conselhos escolares e outros órgãos colegiados já existentes), na busca por soluções de problemas e respeitando as normas instituídas. Manifesta-se assim outra característica dessa tendência: a atenção especial aos aspectos jurídico-normativos relacionados à política de educação.

Embora explicite o compromisso de se almejar, através da educação formal, amplas alterações na estrutura social - identificadas pelo recurso de expressões como transformação social e emancipação, por exemplo -, a base teórica no trato da categoria democracia e a influência do legado escolanovista, principalmente, limitam a tendência em tela ao alcance de, em um ponto máximo, reformas democráticas da educação e da sociedade capitalista. Algo que não está no horizonte de intenções das elites, mas que, através da luta social e em nova conjuntura menos desfavorável aos trabalhadores, pode vir a forçar o Estado a dialogar sobre possíveis meios de apresentar respostas a reivindicações populares.

A quarta e última tendência identificada no debate dos últimos trinta anos sobre democratização da política educacional no Brasil caracteriza-se pelo intento de se promover uma ruptura contra-hegemônica na educação. A tendência de ruptura contrahegemônica não nega os aspectos presentes na tendência anterior, mas, por meio de um movimento de anulação e de conservação, dialeticamente busca elevá-los a um nível superior. Ambas são as tendências que se revelaram mais presentes no período analisado. Apesar da perspectiva de ruptura ser identificada em todas as três décadas, há uma pequena e contínua decrescente quantitativa dos anos 1980 aos atuais.

A intenção de ruptura aborda o processo de socialização do poder na educação e na sociedade enquanto um movimento de disputa política entre projetos em confronto. Assim, a gestão democrática das escolas é entendida de modo inerente a tal sentido teórico-metodológico, tratando-se, portanto, de algo a ser conquistado. Dessa maneira, em que pese certa influência do debate sobre democracia enquanto um valor universal (cf. COUTINHO, 1984), a democracia liberal-burguesa é trabalhada em seus limites, contradições e possibilidades; afastando-se de idealizações ou de posturas deterministas.

A tendência de ruptura com a educação hegemônica considera o processo de democratização escolar em suas várias dimensões, contemplando a defesa das garantias de acesso, de permanência e de qualidade do ensino, bem como reivindica profundas alterações na esfera pedagógica: uma pedagogia contra-hegemônica não descolada das possibilidades reais de sua efetivação, mas crítica e alternativa ao modelo em curso conformado pela tradição da Escola Nova.

$\mathrm{Na}$ tendência de ruptura a escola é interpretada por meio do potencial de se constituir em um núcleo de pressão política junto ao Estado. Para tanto, a abertura à participação ampla dos segmentos escolares e de sua comunidade nos espaços coletivos de planejamento, execução, avaliação e fiscalização se faz inegociável, democratizando o processo de tomada de decisões e visando à transformação democrática e participativa da escola como um todo. Nesse sentido, ganham relevo as propostas dessa tendência voltadas à organização de órgãos colegiados de novo tipo, pelos quais a socialização do poder 
poderá se operar de modo mais dilatado e democrático. Portanto, a perspectiva de ruptura contra-hegemônica não abdica da ideia de participação, mas dialeticamente nega-a e a conserva, elevando-a a um nivel superior.

De todas as quatro tendências, a de ruptura contra-hegemônica é a única que explicita o compromisso com a superação da sociedade capitalista. Isso ocorre de modo mais contundente nos anos 1980, perdendo objetividade nos anos posteriores. Tratase de um processo que exige ser analisado e mediado pelas condições sociais em seu desenvolvimento histórico que, por conta dos limites deste artigo, não poderá ser aqui mais bem detalhado.

\section{A tese da gestão democrática radical}

A concentração do poder político no âmbito da política social no Brasil - com particularidades em cada política setorial - constitui uma manifestação da questão social, expressando determinado estágio de disputa das formas de gestão estratégica organizadas pelo Estado. Tal demarcação teórica insere o debate da democratização educacional, incontornavelmente, no plano da luta de classes que se opera no capitalismo e atribui à questão social uma função de transversalidade junto às principais categorias deste estudo: trabalho, educação e democracia.

Considerando a premissa teórica de que o fundamento ontológico do debate sobre a democratização da educação se localiza na relação orgânica entre política e economia, na qual a socialização do poder político constitui mediação central, tal socialização nas instituições educacionais exige uma gestão democrática radical comprometida substantivamente $^{11}$ com a superação da ordem do capital, através de um processo de anulação, de conservação e de elevação a um nível superior daquilo já conquistado nessa esfera. Uma ação política, portanto, orientada por uma dimensão irrealizável na sociedade capitalista, mas que valha de referência teleológica aos processos coletivos de questionamento, alargamento e superação da gestão democrática possível atualmente.

A noção de gestão democrática radical vincula-se ao conceito de "ocupação da escola” (MARTINS, 2011). Em Martins (2011), a base teórica da noção de "ocupar” sustentase na ontologia da dimensão pública de bens que foram historicamente apropriados privadamente. Tal como a natureza é um patrimônio da humanidade que fora tomado de modo privado na produção social, a educação representa um direito humano hegemonizado pela classe que está no poder. Portanto, “ocupar é mais que um direito, é um dever se entendermos que a vida, e uma vida cada vez mais humanizada e de qualidade, é um direito de todos" (FRIGOTTO, 2011, p. 09).

Pelo viés teórico-político de ocupação da escola, o processo de gestão incide em toda a organização do trabalho pedagógico, abrangendo dialeticamente categorias educativas, políticas, sociais e culturais que solidificam a articulação entre os espaços escolares e sociais (MARTINS, 2011). Dessa forma, tais procedimentos (já em curso em assentamentos do Movimento dos Trabalhadores Rurais Sem Terra) estão ligados ao:

11- No sentido do termo atribuído por Mészáros (2017). 
[...] processo de democratização da gestão escolar, o que não está desvinculado de uma perspectiva social, da democratização nas esferas políticas e sociais e também da perspectiva da sociedade socialista [...]. (MARTINS, 2011, p. 20).

É sabido que importante expressão do poder capitalista está na apropriação privada da riqueza socialmente produzida, estruturado pelo monopólio classista dos meios de produção e, consequentemente, pelo controle organizacional e disciplinar do processo de trabalho. Com base em Marx (1985), é legítimo inferir que nessa lógica geral, que conforma - de maneiras semelhantes, mas não idênticas - tanto o trabalho produtivo quanto o improdutivo, o tempo de trabalho necessário nas instituições educacionais não privilegia ações voltadas à sua democratização, pelo contrário. 0 processo de trabalho reserva àquelas atividades de cunho democratizante um caráter de tempo de trabalho excedente, no qual realizar reuniões do conselho de escola ou com coletivos estudantis, por exemplo, tem certa conotação de sobretrabalho.

A estrutura político-administrativa escolar hegemônica é organizada de modo a oferecer sustento a esse processo de trabalho pari passu à manutenção da concentração do poder político institucional. 0 citado conselho escolar, ao invés de constituir o centro das deliberações em cada escola no qual educadores, familiares e alunos têm o direito e a responsabilidade de exercer a gestão (cf. LIMA, 2000), é reduzido à atividade burocrática e esvaziado de seu potencial político-democratizante capaz de enfrentar a hierarquização tradicional das relações instituídas.

De acordo com a tese defendida, a atuação na escola voltada à sua radical democratização precisa confrontar o estado de alienação inerente aos processos de trabalho parcelados e individualizantes que, na educação, não atribuem qualquer centralidade a atividades potencialmente democratizantes. Desse modo, faz-se necessário incorporar nessa atuação todos os segmentos que a compõem: estudantes, seus familiares, docentes, diretores, merendeiras etc. 0 enfrentamento político não está localizado no embate com um desses segmentos específicos, mas no campo ideológico e, portanto, perpassa toda a escola de maneiras diferentes, dinâmicas e contraditórias (MOREIRA, 2017).

Todavia, a correlação de forças tradicional exige ser questionada, pois buscar a democratização - em um país marcado historicamente pela "revolução passiva" (GRAMSCI, 2000) - privilegiando uma ação junto àqueles sujeitos que já ocupam posições de destaque em relação aos usuários dos serviços, acreditando que com isso será possível alterar essa mesma correlação de forças instituída, é, no mínimo, ingenuidade (MOREIRA, 2018). Trata-se, necessariamente portanto, de um movimento conscientemente guiado pelo tensionamento das estruturas de poder instituídas e pela busca de sua radical democratização, acumulando forças políticas para o enfrentamento coletivo de questões singulares e, sobretudo, daquelas mais bem relacionadas às lutas gerais voltadas ao alcance de um nivel superior de democracia.

A natureza do trabalho desenvolvido em uma instituição educativa possibilita orientar-se por novas formas cooperativas de organização e de poder na escola, por meio de uma gestão compartilhada com maior força diante do Estado e maior legitimidade diante da 
comunidade (PARO, 2016). ${ }^{12}$ Um processo necessariamente dirigido - nos termos de Gramsci (2000) - pela vontade coletiva, visando à passagem do momento egoístico-passional ao ético-político. 0 princípio de gestão democrática da educação no MST (2005, p. 173) orientase em direção teórico-política similar:

a) A direção coletiva de cada processo pedagógico, que vai além dos seus participantes mais diretos, ou seja, educadores/educadoras e educandos/educandas. Isto quer dizer, no caso das escolas de acampamentos e assentamentos, a participação efetiva da comunidade na gestão da escola, bem como a relação desta escola com o conjunto de escolas ligadas ao MST, e sua subordinação (crítica e ativa) aos seus princípios filosóficos e pedagógicos. b) A participação de todos os envolvidos no processo de gestão. Todos devem aprender a tomar decisões, respeitar as decisões tomadas no conjunto, a executar o que foi decidido, a avaliar o que está sendo feito, e a repartir os resultados (positivos e negativos) de cada ação coletiva [...].

Como informa Saviani (1989), política e educação são categorias diferentes que mantêm relação interna de indissociabilidade. ${ }^{13}$ "Com efeito, trata-se de práticas distintas, mas que ao mesmo tempo não são outra coisa senão modalidades específicas de uma mesma prática: a prática social" (SAVIANI, 1989, p. 95). Portanto, nessa mesma perspectiva, "educação e política, pedagogia e ideologia, são consideradas inseparáveis logo a partir dos mais elementares traços constitutivos do processo pedagógico [...]” (LIMA, 2000, p. 76). A sintese dessa unidade entre diversos aponta para o fato de que nas instituições educacionais o essencialmente político requer ser socializado e o fundamentalmente educacional democraticamente concentrado.

Não há consensos generalizantes ou estruturais possiveis de serem alcançados em uma educação tensionada por interesses de classes antagônicas (SAVIANI, 1989). Posto isso, a democratização que aponte para um projeto educacional anticapitalista deve pautar-se pelo dissenso político.

0 consenso é vislumbrado no ponto de chegada. Para se chegar lá, porém, é necessário, através da prática social, transformar as relações de produção que impedem a construção de uma sociedade igualitária. (SAVIANI, 1989, p. 85).

A dimensão social coercitiva do consenso $^{14}$, característica da democracia restrita brasileira, expressa-se em relações gerais e singulares. Assim, parcela representativa dos consensos estabelecidos na educação tende ser determinada verticalmente: ordens fetichizadas por vernizes de acordos.

12 - A criação de um "conselho diretivo" escolhido via eleições, no qual um "coordenador geral de escola" dividiria a direção da instituição com outros três membros do conselho, é uma instigante proposição de Paro (2016). Destaca-se aqui a importância dessas eleições serem diretas e com sufrágio universal, tal como reivindicam os movimentos sociais em defesa da educação pública no Brasil.

13- Isto é, "toda prática educativa, enquanto tal, possui uma dimensão política assim como toda prática política possui, em si mesma, uma dimensão educativa" (SAVIANI, 1989, p. 94).

14 - Um significativo exemplo concreto e contemporâneo daquilo por nós denominado de "dimensão coercitiva do consenso" é o fato de, entre 2013 e 2018, o total de escolas públicas geridas pela Polícia Militar ter crescido 212\%. Confira Camporez (2018). Para uma abordagem teórica mais precisa confira Moreira (2018). 
A democratização radical reivindica a "democratização da cultura" (cf. FREIRE, 2009), na qual se reveste de centralidade o diálogo criticizador em contraponto ao "antidiálogo" vertical, acrítico, autoritário e que "não comunica. Faz comunicados" (FREIRE, 2009, p. 116). Por essa via, a dimensão sociocultural necessita ser transformada através de um processo no qual a instituição de educação:

[...] a partir da composição social dos sujeitos que a constituem, vai inserindo na dinâmica educativa formal os elementos constituintes de sua composição cultural e de seus processos de socialização. (MARTINS, 2011, p. 224).

Nesse sentido, a democratização do poder e da cultura na escola exigem ainda a mais ampla socialização das informações institucionais, democratizando para toda a comunidade escolar o seu acesso, pois, como defende Foucault (1989), saber é poder.

É imperativo que haja um extenso movimento de democratização com potencial de adentrar as práticas educativas intra e extra sala de aula e, dentre outras consequências, reconfigurar o projeto político-pedagógico na perspectiva de um projeto educacional histórico-crítico antagônico de questionamento e ruptura com a ordem. Para tal, o modo de ensino dos conteúdos representa elemento de centralidade, pois "o domínio da cultura constitui instrumento indispensável para a participação política das massas" 15 (SAVIANI, 1989, p. 66). Destarte, a construção de um projeto político-pedagógico orientado por um viés cultural distinto do tradicional se faz mister.

Decerto, tal posicionamento requer, por exemplo, que os grêmios estudantis sejam constituídos e, principalmente, fortalecidos para que sua atuação política entranhe todas as vias que conformam a atual gestão educacional, colocando-se de encontro ao tipo de educação "[...] que não jogue o educando às experiências do debate e da análise dos problemas e que não lhe propicie condições de verdadeira participação" (FREIRE, 2009, p. 101). Por participação, torna-se imprescindivel compreendê-la enquanto ação ativa no âmbito das decisões, sem prejuízo à participação na execução e avaliação (PARO, 2016), socializando, dessa forma, não somente o poder político inerente às principais deliberações institucionais, bem como buscando garantir a unidade teórico-prática entre a política e o financeiro. Como sintetiza Bordenave (1985, p. 12):

Do ponto de vista dos setores progressistas, a participação facilita o crescimento da consciência crítica da população, fortalece seu poder de reivindicação e a prepara para adquirir mais poder na sociedade.

Trata-se de um fortalecimento dos integrantes da escola, em articulação orgânica com a comunidade escolar, que aponte para a politização crítica das relações sociais e amplie o envolvimento junto a outros sujeitos coletivos ainda afastados desse espaço, mas que se colocam na mesma luta por uma educação de viés contra-hegemônico. É nessa relação que movimentos progressistas por outra educação poderão, cada vez mais,

15- A metodologia da "pedagogia revolucionária" é de raro valor neste sentido. Confira Saviani (1989, p. 69-89). 
atuar politicamente na dialética escola-Estado e, concomitante à intervenção no sentido de fazer valer seus direitos, desmistificar as contradições inerentes aos mesmos e à sua condição subalterna na luta de classes.

A construção da escola democrática constitui, assim, um projecto que não é sequer pensável sem a participação activa de professores e de alunos, mas cuja realização pressupõe a participação democrática de outros sectores e o exercício da cidadania crítica de outros actores, não sendo, portanto, obra que possa ser edificada sem ser em co-construção. [...] A luta por uma escola pública e popular implicará um processo de progressiva abertura e inserção comunitárias, mesmo de apropriação criativa da escola pela comunidade, por forma a transformá-la num "centro irradiador da cultura popular" e num "espaço de organização política das classes populares", lugar de associação da educação formal e da educação não formal "à disposição da comunidade, não para consumi-la, mas para recriá-la”'16. (LIMA, 2000, p. 42-3).

Não há projeto anticapitalista se o mesmo não apresentar como fundamento de sua intervenção político-pedagógica a desmistifıcação dos condicionantes que estruturam a sociedade do capital. A gestão democrática radical da educação só se sustenta se articulada indissociavelmente a um projeto educacional voltado para a emancipação humana estruturado por uma educação pública, gratuita, universal e unitária na relação instrução-trabalho. "Entende-se, todavia, em que pese a pluralidade de projetos, que a defesa da escola pública, gratuita, democrática e de qualidade coloca-se como princípio inegociável nessa caminhada" (DOURAD0, 2013, p. 116).

A problematização crítica e permanente sobre tais reivindicações históricas dos trabalhadores, mediada pelo desvelamento da lógica em que se organiza a sociedade de classes capitalista, é condição sine qua non para a formação de uma visão de mundo e um "espírito de cisão" (GRAMSCI, 2007) que possibilitem a compreensão da condição de subalternidade político-econômica na qual se encontra socialmente o indivíduo e, nesse sentido, amplie as possibilidades de "uma nova postura diante dos problemas do seu tempo e de seu espaço” (FREIRE, 2009, p. 101).

Tendo em vista que "a tarefa da democracia socialista é penetrar realmente na inteira vida material de todos os homens, desde a cotidianidade até as questões decisivas da sociedade" (LUKÁCS, 2008, p. 117), a experiência concreta de uma gestão democrática radical guarda potencial de possibilitar aos seus participantes o maior questionamento das ideias hegemônicas intrínsecas à democracia liberal-burguesa. Pelo movimento do real, ampliam-se as condições de mudança na relação política desses sujeitos, coletivamente, com o Estado e com os aparelhos privados de hegemonia da classe trabalhadora na reivindicação dos direitos relacionados à política de educação e demais, pois, segundo Saviani (1989, p. 86):

16- "Orientação expressa no primeiro documento publicado no Diário Oficial do Município de São Paulo (1 Fevereiro de 1989) durante a administração Paulo Freire, intitulado 'Aos que Fazem a Educação Conosco em São Paulo'” (LIMA, 2000, p. 43). 
[...] se a educação é mediação, isto significa que ela não se justifica por si mesma, mas tem sua razão de ser nos efeitos que se prolongam para além dela e que persistem mesmo após a cessação da ação pedagógica.

Noutras palavras: em tempos de hegemonia global da ideologia neoliberal e sua investida contra a organização política dos trabalhadores, os sujeitos que compõem as instituições educacionais - em articulação com coletivos de caráter progressista e/ou anticapitalista - podem se colocar em um patamar político mais elevado na denúncia das expressões da questão social transversais ao âmbito da educação e no pressionamento do poder público para a apresentação de respostas concretas, mesmo que na atual fase do capitalismo brasileiro as políticas sociais estejam profundamente subsumidas ao neoliberalismo. Um movimento dialético entre escola e sociedade civil organizada, que politiza criticamente a educação formal ao mesmo tempo que renova as formas pedagógicas de se fazer política ao incorporar, cada vez mais, a rebeldia criativa da juventude.

A educação, ainda que elemento determinado pela organização social, não deixa de influenciar o elemento determinante, por meio de uma relação de dependência mútua e, contraditoriamente, de relativa autonomia entre ambas (SAVIANI, 1989). Desse modo, a gestão democrática educacional precisa ser compreendida como uma mediação entre aquilo experimentado concretamente dentro da escola e uma prática social voltada para a construção de uma nova sociedade igualitária.

Para [Paulo] Freire, a associação de uma interpretação crítica da realidade a práticas políticas de mobilização organizacional pode gerar novas possibilidades democráticas e apoiar acções de tipo contra-hegemónico [...]. (LIMA, 2000, p. 82).

Por meio da ação política crítica e consciente na vida social, a percepção de que as políticas sociais se encontram inviabilizadas de sua efetivação ampla atualmente pode (re) significar a urgência de se encontrar novas alternativas para a educação e a sociedade. A desigualdade do poder político-econômico contém o germe da resistência, da luta e da transformação, dentro e fora da instituição educacional. E é no processo dinâmico da prática social que residem as possibilidades de compreender mais nitidamente que o “compromisso ético-político não está em colocar o 'trem no trilho', mas sim colocar os ‘trilhos em nova direção”” (MOREIRA, 2017, p. 20).

\section{Conclusões}

Como visto, o fundamento ontológico do debate sobre a democratização da política de educação se localiza na relação orgânica entre política e economia, na qual a socialização do poder político constitui mediação central. A tradição crítico-dialética possibilita compreender a categoria democracia enquanto processo social de socialização do poder político, necessariamente pari passu a do poder econômico. Trata-se de uma relação dialética de unidade na qual o trabalho constitui mediação central e determinante. Por esse ângulo, a construção da democracia orientada pela teoria social de Marx não 
representa a simples ampliação da democracia burguesa (cf. LUKÁCS, 2008). A democracia conflitante com a ordem do capital se formata por meio do movimento dialético de anulação, conservação e elevação a um nível superior, a partir da realidade concreta. $\mathrm{Ou}$ seja: via a própria ordem capitalista.

A formação sócio-histórica brasileira tem, dentre suas características, a concentração do poder político como dada expressão da questão social desde a gênese do capitalismo no país. A conformação da sua democracia do tipo restrita e a estrutural autocracia burguesa (cf. FERNANDES, 2005) imprimem marcas nas relações sociais que revelam uma combinação sui generis no equilíbrio da força e do consenso que garante a manutenção da hegemonia burguesa no Brasil, anuviando as fronteiras entre democracia formal e ditadura bonapartista. Assim, mesmo na atual fase de crise de hegemonia, a aproximação de um regime ditatorial é confundida com mero acirramento da coerção formalmente legal em períodos democráticos. Ou vice-versa.

Contemporaneamente, a questão social tem suas manifestações cada vez mais interpretadas - pelo Estado e por parcela crescente da sociedade civil - como objeto de coerção, rebaixando o sentido político das políticas sociais e inflando a função da força para a manutenção da hegemonia. A ofensiva neoliberal contra a organização política dos trabalhadores, mediada por uma democracia cada vez mais blindada a reivindicações de caráter popular (cf. DEMIER, 2017), expressam-se de maneiras particulares - enquanto momento do universal - nas diversas instituições sociais. No âmbito educacional, aparelhos privados ligados ao empresariado e mesmo segmentos do poder público reivindicam abertamente menos liberdades democráticas para alunos e educadores, sob o pretexto de despolitização da educação e de mais democracia.

A pesquisa realizada revelou que, na produção dos autores que compuseram a amostra, há o comprometimento - em intensidades nem sempre semelhantes - com a interpretação crítica da realidade. De um modo geral, os autores estudados empenham esforços junto ao campo democrático popular de participação da regulação Estatal no que se refere à política de educação. Apesar dos indubitáveis avanços presentes nesse movimento, parte significativa da produção teórica analisada migrou, dos anos 1980 aos atuais, para a defesa de uma gestão democrática na qual a ordem social burguesa é seu limítrofe teleológico.

A análise crítica da gestão democrática das escolas, em contexto atual, passa a exigir a incorporação de um conjunto de mediações sem o qual se corre o risco de deságue em interpretações politicamente anacrônicas. Considerando ainda que o papel do Estado e sua intervenção junto às demandas dos trabalhadores se transfigura de acordo com o período histórico no qual se localiza a correlação de forças entre as classes sociais, a concentração do poder político no âmbito educacional - na qualidade de expressão da questão social - encontra-se interditado de socialização via seus processos formais.

Tendo em vista os resultados da pesquisa aqui sinteticamente apresentados, as características da formação social brasileira, as particularidades da democracia no país, o projeto burguês de educação nacional e o viés reformista impresso em significativa parcela das lutas educacionais ao longo da história brasileira; concluiu-se que o debate dos últimos trinta anos sobre gestão democrática da educação estudado carece de mediação 
com processos que apontem, mais objetiva e concretamente, para um projeto educacional antagônico de ruptura com o capitalismo, mesmo que determinada importante tendência crítica deste debate encontre-se menos imbricada aos limites das ideias hegemônicas de democracia liberal-burguesa.

Há, nessa conclusão, o balanço final do conjunto de textos e autores pesquisados. 0 que não significa que, nesse conjunto, não haja textos e autores que explicitam profundas mediações entre democratização da política educacional e processos de construção do socialismo. Ocorre que a comprovação ou refutação de uma hipótese científica, sobretudo nas ciências humanas, não pode ser determinada pela exceção.

Pode-se inferir, portanto, que a democratização da política de educação, reorientada pelas condições concretas postas, ganha novo relevo tático quando comprometida substantivamente com a superação da ordem do capital (cf. MÉSZÁROS, 2017) e, destarte, vinculada organicamente com um projeto educacional antagônico de ruptura com o capitalismo e contraposto aos limites das ideias hegemônicas de democracia liberalburguesa. Trata-se de uma gestão que se oriente por uma dimensão política inalcançável nessa sociedade, mas que valha de referência teleológica aos processos coletivos de crítica, dilatação e superação da gestão substancialmente democrática possível na ordem do capital.

\section{Referências}

BOBBI0, Norberto. 0 futuro da democracia. São Paulo: Paz e Terra, 2000.

BORDENAVE, Juan E. Díaz. 0 que é participação. São Paulo: Brasiliense, 1985. (Primeiros passos).

CAMPOREZ, Patrik. Número de escolas públicas "militarizadas" no país cresce sob o pretexto de enquadrar os alunos. Revista Época, Rio de Janeiro, 2018. Disponível em: https://epoca.globo.com/numero-deescolas-publicas-militarizadas-no-pais-cresce-sob-pretexto-de-enquadrar-os-alunos-22904768. Acesso em: 14 dez. 2018.

COUTINHO, Carlos Nelson. A democracia como valor universal. In: COUTINHO, Carlos Nelson. A democracia como valor universal e outros ensaios. 2. ed. Rio de Janeiro: Salamandra, 1984. p. 17-50

DEMIER, Felipe Abranches. Depois do golpe: a dialética da democracia blindada no Brasil. Rio de Janeiro: Mauad, 2017.

DOURAD0, Luiz Fernandes. A escolha de dirigentes escolares: políticas e gestão da educação no Brasil. In: FERREIRA, Naura Syria Carapeto (org.). Gestão democrática da educação: atuais tendências, novos desafios. 8. ed. São Paulo: Cortez, 2013. p. 95-117.

FERNANDES, Florestan. A revolução burguesa no Brasil: ensaio de interpretação sociológica. 5. ed. São Paulo: Globo, 2005.

FOUCAULT, Michel. Microfísica do poder. 8. ed. Rio de Janeiro: Graal, 1989. 
FREIRE, Paulo. Educação como prática da liberdade. 32. ed. Rio de Janeiro: Paz e Terra, 2009.

FRIGOTTO, Gaudêncio. Prefácio. In: MARTINS, Fernando José. Ocupação da escola: uma categoria em construção. Cascavel: Unioeste, 2011.

GRAMSCI, Antonio. Cadernos do cárcere. v. 3. Rio de Janeiro: Civilização Brasileira, 2007.

GRAMSCI, Antonio. Cadernos do cárcere. v. 6. Rio de Janeiro: Civilização Brasileira, 2000.

JAMESON, Fredric. 0 pós-modernismo e a sociedade do consumo. In: KAPLAN, E. Ann (org.). 0 mal-estar do pós-modernismo: teorias e práticas. Rio de Janeiro: Zahar, 1993.

LIMA, Licínio C. Organização escolar e democracia radical: Paulo Freire e a governação democrática da escola pública. São Paulo: Cortez: Instituto Paulo Freire, 2000. (Guia da escola cidadã; v. 4)

LUKÁCS, Gyorgy. Socialismo e democratização: escritos políticos 1956-1971. Rio de Janeiro: UFRJ, 2008.

MARTINS, Fernando José. Ocupação da escola: uma categoria em construção. Cascavel: Unioeste, 2011. (Coleção thésis).

MARX, Karl. 0 capital: crítica da economia política. v. 2. Livro I. 2. ed. Trad. Regis Barbosa e Flávio R. Kothe. São Paulo: Nova Cultural, 1985. (Os economistas).

MÉSZÁROS, Istiván. A educação para além do capital. 2. ed. São Paulo: Boitempo, 2008.

MÉSZÁROS, Istiván. Igualdade substantiva e democracia substantiva. Blog Boitempo, 2017. Disponível em: https://blogdaboitempo.com.br/2017/12/19/meszaros-igualdade-substantiva-e-democracia-substantiva/. Acesso em: 06 jan. 2018.

MOREIRA, Carlos Felipe Nunes. 0 trabalho com grupos em serviço social: a dinâmica de grupo como estratégia para reflexão crítica. 4. ed. São Paulo: Cortez, 2017.

MOREIRA, Carlos Felipe Nunes. Trabalho, educação e democracia: tendências do debate sobre democratização da política educacional brasileira nos últimos trinta anos. 2018. Tese (Doutorado em Serviço Social) - Faculdade de Serviço Social, Universidade do Estado do Rio de Janeiro, Rio de Janeiro, 2018.

MST. Movimento dos Trabalhadores Rurais sem Terra. Dossiê MST Escola: documentos e estudos 19902001. Caderno de Educação, Veranópolis, n. 13. ed. esp., 2005.

NEWMAN, Janet; CLARKE, John. Gerencialismo. Educação \& Realidade, Porto Alegre, v. 37, n. 2, p. 353-381, maio/ago. 2012. Disponível em: http://www.scielo.br/pdf/edreal/v37n2/03.pdf. Acesso em: 10 jun. 2018.

PAR0, Vitor Henrique. A utopia da gestão escolar democrática. In: PARO, Vitor Henrique. Gestão democrática da escola pública. 4. ed. São Paulo: Cortez, 2016. p. 13-19. 
SAVIANI, Dermeval. Escola e democracia: teorias da educação, curvatura da vara, onze teses sobre educação e política. 21. ed. São Paulo: Cortez, 1989.

Recebido em: 14.04.2019

Revisado em: 03.03.2020

Aprovado em: 24.03.2020

Carlos Felipe Nunes Moreira é professor na Faculdade de Serviço Social da UERJ. Graduado em serviço social pela UERJ (2006), mestre (2010) e doutor (2018) em serviço social pela UERJ. Pesquisador no Grupo de Estudo e Pesquisa sobre o Serviço Social na Área da Educação (GEPESSE), da Universidade Estadual Paulista Júlio de Mesquita Filho (Unesp). 